\title{
Demanda mapuche: tensión entre identidad y diferencia, ciudadanía y comunidad, particularismo y universalismo*
}

\author{
Angela Boitano G. \\ Universidad Diego Portales, Santiago, Chile. Email: aboitanog@gmail.com.
}

Resumen: La demanda mapuche nos obliga a pensar en un "sujeto incardinado" que sostiene ciertas reivindicaciones propiamente modernas en su reclamo por reconocimiento de la diferencia, al mismo tiempo que desafía la noción de ciudadanía universal y sostiene una demanda anclada territorialmente y basada en un discurso emancipatorio de derechos. En efecto, nos reenfoca en la constitución de una identidad colectiva que es efecto -por una parte- de una exclusión y de un reconocimiento erróneo y -por otra partede un entorno global que hace más visibles los fragmentos no anudados, como su contracara. Finalmente, nos enfrentan a la demanda universal de derecho a la vida significativa. Se propone pensar la identidad desde una perspectiva des-esencializada que enfatice -por una parte- el rol del lenguaje en la estructuración de las relaciones sociales y -por otra- la relevancia de lo nonarrativizado del campo social.

Palabras clave: minoría mapuche, demandas, identidad colectiva, performatividad, ciudadanía, universalismo/particularismo.

\section{Mapuche demand: tension between identity and difference, citizenship and community, particularism and universalism}

\begin{abstract}
Mapuche claim forces us to think of an " incardinated subject” holding certain reivindications strictly modern in their claim for recognition of difference, while challenging the notion of universal citizenship and possing a territorially anchored demand and based on an emancipatory rights discourse. Indeed, it refocusse us on the building of a collective identity which is an effect, on the one hand, of an exclusion and misrecognition and, on the other hand, of a global environment that makes them more visible fragments not tied, as its counterface. Finally, it confonts us to universal demand for the right to a meaningful life. We propose to consider identity from a de-essentialized perspective that emphasizes -firstly- the role of language in structuring social relations and -next- the relevance of the non-narrativized of the social field.
\end{abstract}

Key words: Mapuche minority, demands, collective identity, performativity, citizenship, universalism/particularism. 


\title{
Demanda Mapuche: tensão entre identidade e diferença, cidadania e comunidade, 0 particularismo eo universalismo
}

\begin{abstract}
Resumo: Reivindicação Mapuche nos obriga a pensar de um sujeito incardinado sustentando certas reivindicações estritamente modernas no seu pedido de reconhecimento da diferença, enquanto desafia a noção de cidadania universal e possui uma demanda territorial ancorada e baseada em um discurso emancipatório de direitos. Na verdade, nós foca no fornecimento de uma identidade coletiva que é um efeito, por um lado, de uma exclusão e não reconhecimento, e, por outro lado, em um ambiente global, que torna mais visíveis os fragmentos que não estão vinculados, como o seu homólogo. Finalmente, estamos diante de uma exigência universal do direito à vida significativa. Propomo-nos a considerar a identidade de uma perspectiva de-essencializada que enfatiza- em primeiro lugar, o papel da linguagem na estruturação das relações sociais e, em segundo lugar, pela relevância do não-narrativizado do campo social.

Palavras-chave: Mapuche minoria, demandas, identidade coletiva, performatividade, cidadania, universalismo/particularismo.
\end{abstract}

$$
* * *
$$

\section{Introducción}

Este artículo se enmarca en una investigación ${ }^{1}$ más amplia cuyo objetivo es producir conocimiento acerca de las minorías subordinadas ${ }^{2}$ en relación a la noción de identidad colectiva que subyace a su constitución como grupo cuyo reclamo potencialmente amplía la democracia. Se ha transformado ya en un lugar común señalar que asistimos a la emergencia de identidades no previstas por las narrativas clásicas y a formas de resistencia de las minorías, atípicas. Por otra parte, observamos un proceso de "reetnización” o emergencia de identidades étnicas (Bengoa, 2007: 13) que se ha producido en los últimos 15 años en América Latina, tornando urgente abordar el tema. Se afirman "nuevas" identidades colectivas que cuestionan el Estado republicano, centralizado y homogeneizador, asimismo se reformulan las historias oficiales y se pone en tensión la demanda de igualdad e inclusión que se enfrenta hoy cada vez más con la exigencia de reconocimiento de la diferencia.

En este artículo se propone que de la noción de identidad se derivan consecuencias radicalmente distintas en la esfera política. Si se enarbola la idea de un sujeto (individual o colectivo) portador de la consistencia positiva de un objeto supone un objetivismo que hace muy difícil rearticular las hegemonías. Si por otra parte, se acepta la radical contingencia de la nominación, eso tendría la consecuencia de que siempre sería posible rearticular los discursos hegemónicos. Desde esta perspectiva surge el concepto de "gestión social” (Zizek, 2003: 18) que se propone para superar todo objetivismo. Se trata de concebir a un sujeto privado de toda sustancialidad señalando el carácter performativo de la nominación (Zizek, 2003: 17-8). Pues la nominación contribuiría a estructurar el mundo social, lo que hace de ella un acto extremadamente poderoso que explica las luchas por impo- 
ner las visiones que se conciben como legítimas. Pero no cualquier agente tiene el poder de "notificar" a alguien que posee tal propiedad y en consecuencia prescribir cómo deba comportarse de acuerdo a la esencia social que se le asigna, porque el poder no reside en las palabras, "sino en las condiciones sociales de producción y de reproducción de la distribución entre las clases del conocimiento y reconocimiento de la lengua legítima” (Bourdieu, 2008: 93). No basta con nombrar, hace falta que las palabras además tengan "eficacia simbólica” y ésta está dada por el monto de reconocimiento que se concede al que lo ejerce como alguien habilitado socialmente para ello (Bourdieu, 2008:97).

Precisamente esto es lo que recogería la noción de "punto de acolchado" como momento en que se detiene el deslizamiento metonímico de los significados, haciendo que lo que en sí no es más que pura diferencia o naturaleza puramente performativa se transforme en una "identidad exenta de la interacción relación-diferencia y garantía de su homogeneidad” (Zizek, 2003: 140). Ejemplo de esto es la definición de lo indígena que ha transitado desde "indio indómito" en un contexto en que se necesita justificar la guerra colonial, luego se desplaza hacia la significación "guerrero y libertario” en la lucha por la emancipación del dominio español; ya con la constitución del Estado nación chileno, el indígena se ha concebido como un ser en estado deficiente que requiere blanquearse para estar plenamente integrado a la civilización. En el contexto del socialismo latinoamericano se convierte en el símbolo del nuevo proletario que encarna la resistencia cultural. La dictadura militar los subsume bajo el concepto de "campesinos pobres" y los movimientos ambientalistas hoy los definen como la encarnación de la lucha por la preservación del medio ambiente (cf. Salazar, 1999: 137-173).

\section{El sujeto que "nombra" retroactivamente la demanda}

El sujeto supuesto tras esta búsqueda es un ser-de-lenguaje siempre ligado a un significante, siempre parte de una red intersubjetiva de relaciones simbólicas, que mediante esta significación carga con un mandato que es en definitiva siempre arbitrario -entendiendo por esto que el sujeto nunca sabe qué lugar ocupa en la red simbólica - (cf. Zizek, 2003: 156) precisamente porque su naturaleza es performativa, de modo que su identidad se explica en relación no a propiedades reales que posee, sino al lugar que ocupa en esta red o gran Otro ${ }^{3}$.

Nos preguntamos ¿Qué tipo de diferencias merecen reconocimiento público y/o representación política? (Cfr. Agra, 2000: 137-140) ¿Qué afirmaciones de identidad tienen fundamento en la defensa de relaciones sociales que radicalicen la democracia? Según Laclau, hay que deconstruir la categoría de "sujeto" en lo que respecta a la constitución de las identidades colectivas (Cfr. Laclau, 1987: VII) pues el estadio del capitalismo tardío, desigual y combinado ha dislocado y fragmentado la unidad de las posiciones de sujeto de los diversos agentes. No habría ya -o tal vez nunca hubo- 
un sujeto unitario y fundante, lo que se vincula a los "nuevos antagonismos” (Ibid: X) y a las consiguientes recomposiciones hegemónicas heterodoxas respecto de las categorías clásicas del marxismo.

Es desde una perspectiva crítica que abordamos el supuesto de la identidad que se atribuye a minorías subordinadas pues -en su defensa- se procura representarlas políticamente atribuyendo a éstas una "esencia" (Butler, 2007: 45) que pre-existiría a la demanda. ¿Hay un sujeto o éste surge de la misma estructura de derechos? Sostener que el sujeto pre-existe es hacer invisible la estructura de dominación que produce a los sujetos, naturalizándolos finalmente. Reviste un problema atribuir una identidad común a personas del mismo sexo y/o raza (Ibid: 49) pues eso supone hacer una construcción ontológica independiente de las determinaciones culturales y socio-políticas de todos estos sujetos que se construyen a través de la exclusión. No obstante, esa atribución de una esencia común a los individuos que pertenecen a determinados grupos culturales, tiene la ventaja de promover la representación política que -ciertamente- surge como parte de un espíritu emancipatorio. Pero al omitir las diferencias intragrupales, se comete el error de invisibilizar algunas demandas que surgen de opresiones al interior de los grupos, determinadas por diferencias socio-políticas y culturales. Así, instalada la defensa desde esta perspectiva homogenizadora de los individuos miembros de minorías, se socava la posibilidad de articular prácticas y discursos de resistencia, precisamente por los afanes de universalidad.

\section{Tensión universalismo/particularismo y sus implicancias respecto de la noción de identidad}

Young (1996) ${ }^{4}$ destaca el valor de la universalidad como idea emancipatoria respecto de la sociedad basada en privilegios. No obstante, señala que ésta idea no ha producido igualdad y libertad para todos. En ese sentido propone la "ciudadanía diferenciada" (Young, 1996: 100) como mecanismo de inclusión de personas y grupos que reclaman por el reconocimiento de diferencias específicas porque en un contexto de desigualdad y privilegios para algunos, el universalismo sólo perpetua esta inequidad. La ciudadanía diferenciada apuntaría a: resolver el problema de la ciudadanía general que homogeniza y excluye en ese mismo gesto, proponiendo mecanismos de representación grupal; y otorgar derechos especiales a los grupos minoritarios oprimidos (Ibid).

$¿$ ¿Hay algo prediscursivo que se articula en un discurso adquiriendo visibilidad? o ¿este "algo" surge "en” el discurso producido en medio de relaciones de poder? Butler (2007: 46-9) reflexiona sobre esto a propósito de la categoría de género. Propone pensar la categoría menos como un atributo que como una relación. Pues el problema con las afirmaciones universalistas es que suelen ser prescriptivas y excluyentes y se usan sin considerar lo no narrativizado de los privilegios y subordinaciones en que 
se ubican los individuos ${ }^{5}$. En efecto, la coherencia y la continuidad -propios del concepto de identidad- no son rasgos lógicos o analíticos de la persona, sino más bien normas de inteligibilidad socialmente instauradas y mantenidas.

Butler propone un planteamiento antifundacionista que no implique una identidad como premisa, sino privilegiar el carácter construido del género o etnia. Su aporte se puede resumir en la performatividad del género (Cfr. Butler, 2007: 17-8), lo que podríamos ampliar a cualquier categorización, incluida la etnia. Entendiendo esto de dos maneras: (a) desde la anticipación que conjura su objeto en cuanto esperamos que "actúe una esencia interior que pueda ponerse al descubierto, una expectativa que acaba produciendo el fenómeno mismo" (Ibid); (b) como un acto que no es único, sino una repetición y un ritual que consigue su efecto a través de la naturalización en el contexto del cuerpo, entendido como una duración temporal sostenida culturalmente (Ibid). Si el género es performativo, significa que se construye a través de actos, no es un rasgo "interno", es un "efecto" de gestos y actos naturalizados. ¿Puede ser trasladada la teoría de la performatividad a las cuestiones de raza? Sí, si es que se trata finalmente de desnaturalizar las categorías que nos permiten hacer diferencias, teniendo presente entonces que el género $-\mathrm{y}$ tal vez la raza- es además de performativo, normativo, es decir, presuponen y deciden por adelantado lo que puede y no puede formar parte de esa descripción.

Benhabib, propone una teoría interactiva relacional de la identidad. Construye el concepto de "universalismo interactivo"(1990b: 127) que reconoce como punto de partida para la reflexión y la acción al sujeto "incardinado" y "arraigado". Esta teoría de la identidad supone que la naturaleza interna no es dada e inmutable, que es la interpretación de las necesidades la que permite conocer los motivos, la historia, las fantasías y anhelos de las personas, sin relegarlos a la esfera privada. Desde esta perspectiva lo que puede fundamentar una moral universalista es la noción de "discurso práctico" como recurso que media entre el punto de vista del(los) otro(s) "generalizado(s)" y el(los) otro(s) "concreto(s)", al sintetizar la justicia con la solicitud, la autonomía con "entrar en contacto" (Benhabib, 1990a: 19).

Finalmente, lo que está en juego es la tensión entre universalismo y particularismo. No habría un sujeto "tras” estas demandas de derechos. Al menos no ese individuo autónomo, desvinculado, racional de las teorías universalistas del contrato, que se conceptualiza como self desincardinado y desarraigado (Benhabib, 1990b: 126-7) que produce la exclusión de toda aquella experiencia que no refleje a este otro generalizado (que es masculino, occidental, urbano, de cierta clase). Este "otro generalizado" (Cfr. Benhabib, 1990b) se concibe como el paradigma desde el cual comprender a todo la especie humana. Desde ese lugar se piensa la imparcialidad moral como el horizonte en el cual los individuos se conciben como iguales en sus derechos y demandas, y esto constituye la esfera pública de la justicia, el lugar donde se transan demandas, se administra el conflicto y se distribu- 
yen recompensas. El problema es que este gesto inaugura la esfera privada que queda excluida de la justicia. Con éste ser generalizado quedan excluidas las mujeres, los pobres, los indígenas, en síntesis: las minorías subordinadas, con todo su mundo significativo. En el caso de la exclusión de las mujeres y su experiencia, resulta que no queda regulada racionalmente la esfera privada, quedan en el mismo eje de la nutrición y la reproducción, un lugar por el que “no ha pasado el espíritu civilizador” (Ibid: 133-4).

No hay universalidad, en tanto ésta presupone que "los casos semejantes deben ser tratados de manera semejante” (Ibid: 141) y sabemos lo difícil que es determinar qué constituye una situación "semejante” o qué significaría para otro estar en una situación semejante a la propia. La teoría moral universalista “descuida esa moralidad intencional de la vida cotidiana y supone que el punto de vista público de la justicia y nuestras personalidades cuasi públicas en tanto que individuos portadores de derechos, constituyen el centro de la teoría moral” (Ibid, 142). Taylor diría que lo que está en juego es la política de la igualdad que exige igual respeto a las personas en un gesto ciego a la diferencia versus una política de la diferencia que reclama el reconocimiento e incluso el fomento de la particularidad (Taylor, 1997: 308).

\section{Identidad y narrativa}

La propuesta es pensar una identidad des-esencializada. Se trata de criticar la idea usual de que cuando hablamos de algo estamos dando cuenta de características o propiedades "reales" de ese objeto, creemos que estamos definiendo la "esencia” de tales términos. Laclau señala que es imposible definir la esencia o propiedades reales de un concepto o cosa, a menos que éste sea designado siempre con el mismo significante -núcleo de la identidad-que signifique siempre lo mismo en todos los mundos posibles. Lo que está en juego es qué punto nodal totalizará en su serie de equivalencias a estos elementos flotantes que supone la emergencia de estas identidades fragmentadas (cf. Zizek, 2003: 126), qué “Uno” englobe el campo y efectúe la identidad. Precisamente esto es lo que recogería la noción de “punto de acolchado”. Éste totaliza la ideología deteniendo el deslizamiento metonímico de los significados, haciendo que lo que en sí no es más que pura diferencia, naturaleza puramente performativa se transforme en una “identidad exenta de la interacción relación-diferencia y garantía de su homogeneidad” (Zizek, 2003: 140), olvidando en este gesto que el sujeto supuesto tras esta búsqueda es un ser-de-lenguaje siempre ligado a un significante, siempre parte de una red de intersubjetiva de relaciones simbólicas, que mediante esta significación carga con un mandato que es en definitiva siempre arbitrario (Ibid: 156) precisamente porque su naturaleza es performativa, de modo que su identidad se explica en relación no a propiedades reales que posee, sino al lugar que ocupa en la red simbólica.

\section{Cito a Benhabib:}


las identidades colectivas están formadas por "hebras de narraciones competitivas y contenciosas en las que compiten entre sí aspiraciones universalizantes y memorias particularistas para crear síntesis narrativas temporarias, que son a su vez cuestionadas y se ven atravesadas por nuevas divisiones y debates” (2005: 69).

Hablar de identidades "blandas” (Cfr. Rachik, 2006) se relaciona con el entorno en que éstas se constituyen lo cual permite reflexionar acerca de la eventual bondad de la porosidad de las fronteras hoy. Pues el terreno en que éstas se constituyen no se trataría sólo de fronteras geográficas, sino de desdibujamiento de fronteras culturales, que se traducen -por ejemplo- en el mayor acceso de minorías étnicas a formación profesional con la consecuente ampliación de horizontes de expectativas, la incorporación de discursos inclusivos que legitiman la diferencia, etc. ¿Por qué podrían poner en jaque a una democracia liberal sólida y no -por el contrario- robustecerla, enriquecer la diversidad democrática existente?

Las comunidades culturales se constituyen en torno a la adhesión de sus miembros a estilos de vida que suponen creencias, valores que afectan la pertenencia o exclusión, hecho por el cual son prescriptivas para su identidad (Tugendhat, 1998: 204-5). Pero éstas serían "blandas” entendiendo por esto que son menos compactas, plagadas de inconsistencias y discursos provenientes de tradiciones no sólo distintas sino que incluso contrapuestas. Es el caso de ser una mujer musulmana moderna que adhiere a la igualdad de género, o aquel en que se es católico dispuesto a aceptar la legalización del aborto terapéutico (en Chile) o practicar técnicas budistas de meditación al mismo tiempo que ganarse la vida en la especulación bursátil. Todos ejemplos de reapropiaciones sui generis de tradiciones culturales.

Si se examina el discurso reivindicatorio de las organizaciones que representan la demanda mapuche podemos encontrarnos con la tensión universalismo / particularismo que piensa desde la comunidad y no desde la ciudadanía (cf. Bengoa, 2006). En ese sentido, podemos tal vez verificar una trayectoria distinta que nunca apuntó a la inclusión sino al reconocimiento de la diferencia y a un pensamiento de la contingencia. Respecto de esta temática es pertinente revisar la propuesta de Rorty acerca de la insistencia de la perspectiva filosófica en pensar la universalidad. Este autor nos reenfoca en la aceptación de la contingencia. Desde este punto de vista, sería más sensato hacer una defensa de los derechos de las minorías prescindiendo de la necesidad y aceptando la contingencia. Es posible que la ética habermasiana sea una respuesta a esta tensión. Benhabib describe el modelo de las interpretaciones de la necesidad comunicativa (1990b: 144) basado en Habermas. Esta ética comunicativa proporcionaría un marco a la generación de universalidad dialógica e interactiva. Asimismo, permitiría que los actores sociales y políticos puedan "definir sus identidades concretas sobre la base del reconocimiento de la dignidad de cada cual en tanto que otros generalizados”6 (Benhabib, 1990b: 145), en una lógica que generaría una ampliación del dominio de objeto de la teoría moral, incluyendo 
no solo los derechos abstractos que corresponden a cada uno en tanto ser humano perteneciente a una comunidad lingüística sino también a las necesidades de los individuos concretos, "no solo justicia sino buena vida, dentro de una perspectiva anticipatoria-utópica” (Benhabib, 1990b: 145). Si bien Habermas permitiría comprender estas dos esferas pública y privada, diferenciando sistema y mundo de la vida, según Benhabib no se haría cargo del "subtexto de género" (cf. Benhabib, 1990a: 17), ficcionando nuevamente la universalidad y olvidando que las identidades son incardinadas bajo diversas formas, una de las cuales es el género ${ }^{8}$.

En efecto, hablar de identidades blandas es coherente con la propuesta de comprender las identidades prescindiendo del esencialismo y acercándose a la idea de identidad narrativa. Usualmente cuando se habla de un "nosotros" se piensa en una identidad sin fisura, una unidad, lo cual es una ficción, que si bien ha servido como idea emancipatoria en las luchas sociales, sus consecuencias pueden ser desastrosas en tiempos en que se revalora la diferencia.

\section{Demanda ancestral y discurso "moderno"}

La demanda mapuche pone en tensión la aspiración universal a la libertad y la autonomía -que se verifica en la posibilidad de elegir el modo de vida, la adscripción a una determinada cultura y los modos como quieren relacionarse entre ellos mismos y con otros en tanto ciudadanos que determinan cuál es su lengua oficial, las tradiciones que les son relevantes, etc.- y el particularismo que supone posicionarse como indígena. El universalismo pretende borrar las diferencias raciales, de clase, de género y el particularismo las reestablece. Según Tugendhat, "no son dos tendencias que se producen uno después del otro sino actitudes coexistentes y no necesariamente contrarias” (2002: 59), formarían parte de la vida humana, siendo la primera -el universalismo- una categoría moral que instala la idea de altruismo o respeto, no de simpatía y amor; sentimientos estos últimos que se reservan para el polo particularista.

Las reivindicaciones indígenas evocan la ancestralidad del territorio y la necesidad de recuperarlo como espacio de reencuentro y apropiación cultural, al tiempo que "modelan un tipo de ciudadanía diferente fundamentada en un proyecto 'intercultural', según el cual es necesario que los indígenas se hagan competentes en el mundo 'occidental', sin renunciar a su 'identidad' indígena, para asumir con responsabilidad sus nuevos derechos y ejercer plenamente la ciudadanía intercultural” (Del Cairo y Rozo, 2006: 111) que surge en las democracias liberales como alternativa a la ciudadanía cívica basada en la individualización de derechos, proponiendo "asignación de derechos colectivos en virtud del reconocimiento de identidades culturales minoritarias al interior de esas democracias” (Del Cairo y Rozo, 2006: 112).

Los problemas para implementar estas políticas surgen de la visión 
estática y esencialista de lo indígena que proviene de la mirada hegemónica del estado y que se traduce en leyes ciegas a la diferencia y en la dificultad para pensar en un indígena urbano y moderno como sujeto plenamente étnico. Las reservas o reducciones indígenas ${ }^{9}$ son una prueba concreta no sólo del dominio que se ejerce sobre las minorías, sino además de la esencialización de la identidad étnica. Es más, esta misma situación muchas veces es usada como una estrategia por los miembros de estos grupos étnicos quienes evocan estos estereotipos esencialistas y externos sobre lo indígena en un acto performativo que busca instalar la idea de que "son" indígenas. Esto nos pone en contacto con las paradojas que se advierten en las representaciones que los mismos indígenas construyen acerca de su identidad.

Por una parte, es un intento por situarse en una dinámica social donde estas reivindicaciones fluctúan de acuerdo a escenarios y oscilan desde la visión externa a los indígenas y la impugnación a la esencialización que se advierte desde el Estado. Lo que los indígenas a veces muestran como su cultura es estratégico, la esencia se reifica con fines políticos. Salazar y Pinto (1999: 150) -citando a Bengoa- señalan que los mapuche cerraron fila en torno a su cultura como reacción al acoso de la sociedad chilena, antes de la penetración chilena en la Araucanía. En otras palabras, antes del siglo XIX su identidad cultural se sustentaba en el reconocimiento de la autonomía como pueblo prescindiendo de la noción de “pureza racial” que es característico de las sociedades amenazadas.

¿Hay contradicción en afirmar el derecho a la inclusión junto con la demanda de un tratamiento diferencial? No la habría en aquellos casos en que para garantizar la participación se debe atender a la diferencia, porque no se trata de compensar para terminar "normalizando", es decir eliminar la diferencia. Se trata, por el contrario, de "desnormalizar" la forma en que las instituciones formulan sus reglas. Se trata de no tipificar la diferencia como conducta desviada identificándola con estigma y desigualdad (cf. Young, 1996: 124). La política moderna promueve la universalidad de la ciudadanía en el sentido de la inclusión y la participación. Pero la realización de este ideal se ve obstaculizada cuando se exige que las personas adopten una perspectiva universal y abandonen la percepción que se deriva de su experiencia y posición particular.

Esto último se explica en tanto la política de la diferencia reclama reconocimiento y estatuto de algo que no es universalmente compartido (la diferencia) mediante el reconocimiento universal de la identidad, es así que "la exigencia universal impulsa la admisión de la especificidad” (Taylor, 1997: 305). Finalmente, una idea interesante nos transmite Rorty (cf. 1991: 45-63) para analizar el discurso que articula el pueblo mapuche en su reivindicación. Este autor propone un léxico que gire en torno a las nociones de metáfora y de creación de sí mismo y no en torno a las nociones de verdad, racionalidad y obligación moral. Tal vez es una de las salidas a la aporía en que se encuentran hoy los discursos en conflicto. La demanda mapuche nos obliga a pensar en el sujeto incardinado que sostiene ciertas 
reivindicaciones propiamente modernas en su reclamo por reconocimiento de la diferencia, al mismo tiempo que desafía la noción de ciudadanía universal y sostiene una demanda anclada territorialmente y basada en un discurso emancipatorio de derechos. En efecto, nos reenfoca en la constitución de una identidad colectiva que es efecto -por una parte- de una exclusión y de un reconocimiento erróneo y -por otra parte- de un entorno global que hace más visibles los fragmentos no anudados, como su contracara. Finalmente, nos enfrentan a la demanda universal de derecho a la vida significativa. Se trata de poner la filosofía al servicio de la práctica democrática que supone ampliar la solidaridad, revisar los léxicos desde los que pensamos e interactuamos con otros (cf. Rorty, 1991: 215). 


\section{Notas}

${ }^{*}$ Una versión de este artículo fue presentada en el Simposio Movimientos Sociales y Acción Colectiva, en el marco del "II Congreso de ciencia, tecnología y culturas. Diálogo entre las disciplinas del conocimiento. Mirando el futuro de Latinoamérica y el Caribe”, Santiago octubre-noviembre, 2010

${ }^{1}$ Entre sus objetivos específicos, esta trabajo se propone: (1) abordar la noción de minoría en función de los modos de subordinación que las constituyen, sus demandas específicas asociadas a determinadas prácticas de resistencia, sus herencias teóricas y contexto sociopolítico relevante; (2) estructurar una concepción de identidad colectiva desde una perspectiva que otorgue un papel central al lenguaje en la estructuración de las relaciones sociales, lo que supone una crítica a la noción esencialista y universalista de identidad; (3) considerar no sólo la centralidad del texto sino la importancia del contexto o materialidad del campo social, lo no narrativizado que da cuenta de los límites del lenguaje, en ese sentido se asume la determinación que impone el capitalismo global; (4) examinar el aporte del multiculturalismo, del comunitarismo y de la teoría del reconocimiento en la comprensión de las minorías subordinadas; (5) observar localmente el "conflicto mapuche"1 desde los léxicos que formulan las partes, entendiéndolos como "léxicos del conflicto" (cf. Rorty, 1991: 67-72) desde los cuales no hay forma de salir hacia un meta-léxico.

${ }^{2}$ Uso este concepto de subordinación en una clara alusión a Laclau. Para éste el proyecto socialista es una radicalización de la democracia, una articulación de las luchas contra las diferentes formas de subordinación (clase, sexo, raza y todas las que se subsumen bajo movimientos ecológicos, antinucleares, anti-institucionales). Laclau habla en tal sentido de una democracia "radicalizada y plural”. Este proyecto supone abandonar ciertos supuestos epistemológicos del Iluminismo lo que implica una crítica al racionalismo y al esencialismo, pues a través de ella se podría dar cuenta de manera adecuada de la multiplicidad y diversidad de luchas políticas contemporáneas que se caracterizan por la emergencia de identidades populares y colectivas que no responden a la divisoria de clases (cf. Laclau, 1987: prefacio).

${ }^{3}$ Término utilizado por Lacan para designar un lugar simbólico -el significante, la ley, el lenguaje, el inconsciente- que determina al sujeto, a veces de manera exterior a él, y otras de manera intrasubjetiva, en su relación con el deseo. Se lo puede escribir con una mayúscula, y se opone entonces al otro con minúscula, definido como otro imaginario, o lugar de la alteridad en espejo. Pero también puede recibir la grafía "gran Otro» o «gran A», oponiéndose entonces al pequeño otro, o al pequeño a, definido como objeto (pequeño) a. Como todos los freudianos, Lacan plantea la cuestión de la alteridad, es decir, de la relación del hombre con lo que lo rodea, con su deseo y con el objeto, en la perspectiva de una determinación inconsciente. Lacan resalta lo que diferencia radicalmente al inconsciente freudiano (como otra escena o tercer lugar que se sustrae a la conciencia) de todas las concepciones del inconsciente derivadas de la psicología. De allí su terminología específica (Otro/otro) que diferencia lo concerniente al tercer lugar (es decir, la determinación por el inconsciente freudiano, Otro) de lo que es propio de la pura dualidad (otro) en el sentido de la psicología.

${ }^{4}$ En: Castells, C. (Compiladora) (1996) Perspectivas feministas en teoría política. Barcelona: Paidós.

${ }^{5}$ Es lo que Zizek (cf. 2003: 142-3) señala al explicar la función del point de capiton. Éste sería un punto a través del cual el sujeto es "cosido" al significante, al mismo tiempo el que 
lo interpela a transformarse en sujeto mediante la subjetivización de la cadena del significante. En efecto, la significación tiene un carácter retroactivo, pues sería el punto en que un significante fija retroactivamente el significado de la cadena, “cose” el significado al significante, deteniendo así el deslizamiento del significado.

${ }^{6}$ El concepto “otro generalizado” se usa en relación con el término “otro concreto”. Benhabib señala que el reconocimiento del otro generalizado es necesario pero no suficiente para definir una perspectiva moral, necesita del reconocimiento previo de la dignidad moral del otro concreto, asumiendo los sesgos propios de la justicia basada en principios universalistas (1990b: 144-5). Se trata -mediante el concepto de "otro concreto"- de rescatar la perspectiva de los individuos con una historia, una identidad y una constitución afectiva-emocional concreta, asimismo de comprender las necesidades del otro, sus motivaciones y deseos; involucrados en relaciones regidas por normas de equidad y reciprocidad complementaria, que serían más privadas que institucionales (de amor, amistad y cuidado). El intento de Benhabib, en sus palabras, es relevar "no sólo la humanidad, sino la individualidad" (1990b: 140) mediante las categorías morales de responsabilidad, vinculación, colaboración.

${ }^{7}$ Young, Fraser, Benhabib y Markus coinciden en que la dicotomía público/privado como principio de organización social, y su articulación ideológica en diversas concepciones de razón y de justicia, van en detrimento de las mujeres. Para Fraser ello resulta en la mistificación de las relaciones género-poder que constituye el subtexto de la economía moderna y del estado. Asimismo sostiene que esto daría cuenta de una represión de la diferencia de las mujeres y su exclusión de lo público. Benhabib critica la trivialización de las perspectivas morales de las mujeres (en su diálogo con la polémica Kolhberg-Gilligan), por su parte Markus releva la dicotomía que produce el doble vínculo entre hogar y trabajo. En Teoría feminista y teoría crítica. Valencia: Edicions Alfons el Magnánim, Generalitat Valenciana. 1990.

${ }^{8}$ En este punto Benhabib asume la crítica que Fraser hace a la distinción sistema-mundo de la vida habermasiana. Fraser señala que la distinción sistema-mundo de la vida no es análoga a la distinción público-privado, pues no ubica a la familia en el lugar de un refugio que ampara del frío sistema, sino que la ve como un lugar de "cálculo egocéntrico, estratégico e instrumental... y lugar de intercambios explotadores de servicios, trabajo, dinero y sexo, por no mencionar que, frecuentemente, es lugar de coerción y violencia” (Benhabib, 1990a: 17).

${ }^{9}$ Esta figura se inserta en el contexto de la etapa de la anexión definitiva de la Araucanía al territorio chileno, que se extiende desde 1862 a 1881. La reducción es la fórmula legal que se adopta luego de la guerra de apropiación, se trata de "pequeñas extensiones de tierra, de dominio común e inalienable, que se entregaban a título de merced y cuyo objetivo era arraigar a los indígenas, transformándolos en una sociedad agrícola; de ese modo podía ejercerse mayor control sobre ellos” (Salazar y Pinto, 1999: 152). 


\section{Bibliografía}

Bengoa, J. (2006), La comunidad reclamada. Identidades, utopías y memorias en la sociedad chilena actual. Catalonia, Santiago de Chile.

Benhabib, S. (2005), Los derechos de los otros. Gedisa, Barcelona.

Ídem (1990), Teoría feminista y teoría crítica. Edicions Alfons el Magnánim, Generalitat Valenciana (Ed. Benhabib y Cornell), Valencia.

Ídem (1990a), “Introducción: Más allá de la política de género”. En Benhabib, 1990: 9-28.

Ídem (1990b), "El otro generalizado y el otro concreto: la controversia Kohlberg-Gilligan y la teoría feminista”. En Benhabib, 1990: 119-149.

Bourdieu, P. (2008), ¿Qué significa hablar? Economía de los intercambios lingüísticos. Akal, Madrid.

Butler, J. (2001), Mecanismos psíquicos del poder. Cátedra, Madrid.

Ídem (2007), El género en disputa. Paidós, Barcelona.

Castells, C. (comp.) (1996), Perspectivas feministas en teoría política. Paidós, Barcelona.

Del Cairo, C. y E. Rozo, (2006), “Políticas de identidad, ciudadanía intercultural y reivindicaciones territoriales indígenas en dos localidades amazónicas”. En Revista Universitas Humanísticas $\mathrm{N}^{\circ} 61$ enero-junio de 2006, 107-134.

Fornet-Betancourt, R. (2002), “Filosofía e interculturalidad en América Latina: intento de introducción no filosófica”. En González, 2002, 123-140.

Fraser, N. y Honneth, A. (2006), ¿Redistribución o reconocimiento?. Un debate político-filosófico. Morata, Madrid.

González, G (coord.) (2002), El discurso intercultural. Prolegómenos a una filosofía intercultural. Biblioteca Nueva, Madrid.

Glover, J. (2003) “Naciones, identidad y conflicto”. En McKim, R. y J. McMahan, 2003: 27-52.

Honneth, A. (1997), La lucha por el reconocimiento. Crítica, Barcelona.

Ídem (2007), Reificación. Un estudio en la teoría del reconocimiento. Katz Editores, Buenos Aires.

Jameson, F. y Zizek, S. (1998,) Estudios culturales: reflexiones sobre el multiculturalismo. Paidós, Buenos Aires. 
Kymlicka, W. (1996), Ciudadanía multicultural. Una teoría liberal de los derechos de las minorías. Paidós, Barcelona.

Laclau, E. y Mouffe, C. (1987), Hegemonía y estrategia socialista. Hacia una radicalización de la democracia. Siglo XXI, Madrid.

Lyotard, J.-F. (1992), La condición posmoderna. Planeta Agostini, Madrid.

McKim, R. y J. McMahan (2003), La moral del nacionalismo. Dilemas identitarios en la era de la globalización. Gedisa, Barcelona

Rachik, H. (2006), “Identidad dura e identidad blanda”. En Revista Cidob d'Afers Internacionals, 2006: 9-20.

Ricoeur, P. (2006a), Caminos del reconocimiento. FCE, México.

Ídem (2006b), Sí mismo como otro. Siglo XXI, México.

Rorty, R. (1991), Contingencia, ironía y solidaridad. Paidós, Barcelona.

Salazar, G. (1990), Labradores, peones y proletarios. Formación y crisis de la sociedad popular chilena del siglo XIX. SUR, Santiago, Chile.

Salazar, G. y Pinto, J. (1999), Historia contemporánea de Chile, vol I y II. LOM, Santiago de Chile.

Taylor, C. ( 1994), La ética de la autenticidad. Paidós, Barcelona.

Ídem (1997), Argumentos filosóficos; Paidós, Barcelona.

Ídem (1996), Fuentes del yo. La construcción de la identidad moderna. Paidós, Barcelona.

Ídem (2003), “Nacionalismo y modernidad”. En: McKim, R. y J. McMahan, 2003: 53-86.

Ídem (2006), Imaginarios sociales modernos. Paidós, Barcelona.

Todorov, S. (2008), La vida en común. Taurus, Buenos Aires.

Ídem (2005), Nosotros y los otros. Siglo XXI, México.

Tugendhat, E. (1998), Ser Verdad y Acción. Gedisa, Barcelona.

Ídem (2002), Problemas. Gedisa, Barcelona.

Valenzuela, S.; Tironi, E. y Scully, T., eds. (2006), El eslabón perdido. Familia, modernización y bienestar en Chile. Taurus, Santiago, Chile. 
Vattimo, G. y otros (1990), En torno a la posmodernidad. Anthropos, Barcelona.

Villoro, L. (1998), Estado plural, pluralidad de culturas. Paidós y Facultad de Filosofía y Letras UNAM, México.

Young, I. M. (1990), “Imparcialidad y lo cívico público. Algunas implicaciones de las críticas feministas a la teoría moral y política”. En Benhabib, 1990: 89-118.

Ídem (1996), "Vida política y diferencia de grupo: una crítica del ideal de ciudadanía universal”. En: Castells, C. (comp.) 1996: 99-126.

Zizek, S. (2003) El sublime objeto de la ideología. Siglo XXI, Buenos Aires. 